\title{
Analysis, Distribution, and Dietary Exposure of Glyoxal and Methylglyoxal in Cookies and Their Relationship with Other Heat-Induced Contaminants
}

\section{GEMA ARRIBAS-LORENZO AND FRANCISCO J. MORALES*}

Consejo Superior de Investigaciones Científicas, Instituto del Frío-ICTAN, Jose Antonio Novais 10, 28040 Madrid, Spain

\begin{abstract}
Thermal processing of food leads to the formation of dicarbonyls such as glyoxal (GO) and methylglyoxal (MGO), which are potentially harmful because they are precursors of advanced glycation end products (AGEs). GO and MGO formation was examined during the baking process of cookies as cookies are a widely distributed food commodity in Western diets. GO and MGO were chromatographically analyzed after employment of an improved method of derivatization with orthophenylenediamine to produce stable quinoxaline derivatives. Sample extraction, cleanup, and chromatographic conditions were evaluated to provide an in-house validated procedure for $\mathrm{GO}$ and MGO analysis in cookies. Quantification limits were set at 1.5 and $2 \mathrm{mg} / \mathrm{kg}$ for GO and MGO, respectively, with an average recovery of $103 \%$ and a calculated precision lower than $7 \%$. Studies were carried out both on laboratory-scale cookies under controlled conditions and on commercial samples as well. GO and MGO values in commercial cookies ranged from 4.8 to $26.0 \mathrm{mg} / \mathrm{kg}$ and from 3.7 to $81.4 \mathrm{mg} / \mathrm{kg}$, respectively. Commercial cookies made from ammonium bicarbonate and fructose showed the highest levels of MGO. Dicarbonyls were rapidly formed on the upper side of the cookie regardless of the shape or thickness of the samples, confirming there was a surface effect. Under controlled baking conditions, the formations of GO and MGO were linearly correlated with baking time. MGO formation was related with acrylamide, a heat-processing contaminant, in commercial cookies, but this relationship was not observed for 5-hydroxymethylfurfural. Dietary exposure of the Spanish population to GO and MGO from cookies was estimated to be 213 and $216 \mu \mathrm{g} /$ person/day, respectively.
\end{abstract}

KEYWORDS: Glyoxal; methylglyoxal; cookies; acrylamide; hydroxymethylfurfural

\section{INTRODUCTION}

Since the last century, R-dicarbonyl research has become an interesting field in both food chemistry and medical science, mainly due to the implications of R-dicarbonyls in public health (I-3). Glyoxal (GO) and methylglyoxal (MGO) have been given special attention because they are reactive intermediates formed by heat processing such as roasting, frying, and baking, as well as by food storage. R-Dicarbonyls are not only known to be important precursors of color and aroma substances but also lead to protein modifications with nutritional consequences. In vivo, dicarbonyls react irreversibly with proteins, forming advanced products analogous to those found in nonenzymatically glycosylated proteins, which are characteristic in aging, atherosclerosis, and diabetic and uremic subjects (4). Their presence suggests potential health risk issues related to mutagenicity and carcinogenity $(5,6)$, with GO causing DNA lesions (7) both in vitro and in vivo studies. MGO inhibits protein, DNA, and RNA synthesis in villus and crypt cells as well as in colonocytes, which are associated with genotoxicity in experimental animals (6). However, information about the effects on humans is limited and basically related to allergic reactions $(8,9)$. The potential pathophysiological role of $\mathrm{GO}$ and $\mathrm{MGO}$ is therefore under investigation in the biomedical area due to the toxicity of these compounds (10). 
In food, R-dicarbonyls are formed by the reaction of amino groups in proteins with reducing sugars (Maillard reaction), by the degradation of sugars during caramelization, and by lipid peroxidation, apart from there being an enzymatic origin in fermented foods (II-13). These toxic carbonyl species have been found in several foods such as honey, with levels in the ranges of $0.2-2.7$ and $0.4-5.4 \mathrm{mg} / \mathrm{kg}$ for GO and MGO, respectively (14), and in fermented products such as wine (up to $1556 \mu \mathrm{g} / \mathrm{L}$ ) $(15)$ and beer (230-1000 $\mu \mathrm{g} / \mathrm{L}$ ) (16), where they are enzymatically formed. In addition, they have been detected in a variety of fermented products, edible oils (up to $6.5 \mathrm{mg} / \mathrm{kg}$ for sardine oil) (17), and bakery products such as bread or toast containing amounts of 0.3 and $0.79 \mathrm{mg} / \mathrm{kg}$ for GO and MGO, respectively (I8).

Various chromatographic methods have been extensively described in the scientific literature for measuring Go and MGO, especially high-performance liquid chromatography (HPLC)-based procedures, capillary electrophoresis, and gas chromatography. Derivatization of R-oxoaldehydes with diamino derivates of benzene such as o-phenylenediamine (OPD) and conversion into corresponding quinoxaline derivates with UV detection has been reported as allowing a more specific estimation of these compounds, especially if used in conjunction with $\operatorname{HPLC}(19,20)$.

A number of studies have reported the formation of $R$ dicarbonyls resulting from carbohydrate and amino acid reaction during thermal treatment of foods, conditions that also favor acrylamide (AA) and 5hydroxymethylfurfural (HMF) formation. AA and HMF have been defined as heat-induced processing contaminants potentially harmful to humans $(2 \mathrm{I}, 22)$. Further studies on $G O$ and MGO formation pathways are necessary because they may provide new information about the dynamics of these toxicants in food and, subsequently, potential mitigation strategies. Until now, knowledge of these reactive dicarbonyls in cookies, as well as their connection with acrylamide formation, has been limited, despite evidence indicating the important role they play in acrylamide genesis (23). Furthermore, GO and MGO levels in cookies have been poorly described so far.

These observations have stimulated our interest in investigating reactive dicarbonyl formation with respect to the formation of new processing contaminants. With this in mind, an in-house validated HPLC-UV method for the determination of $G O$ and $M G O$ in cookies has been developed. Additionally, their relationship with AA and HMF was also studied to get further insight into their formation dynamics and finally an estimation of exposure from cookies to these dicarbonyls.

\section{MATERIALS AND METHODS}

Chemicals. HPLC grade methanol was purchased from LabScan (Dublin, Ireland). Acrylamide (99\%), 5hydroxymethylfurfural, $G O$ and $M G O$ solutions (40\%in water $w / v)$, OPD, quinoxaline (Q), 2methylquinoxaline (2-MQ), and 5-methylquinoxaline (5-MQ) were supplied by Sigma (St. Louis, MO). Sodium dihydrogen phosphate monohydrate and glacial acetic acid as well as formic acid were acquired from Merck (Darmstadt, Germany). The following materials were also used: ultrapure water (Milli-Qsystem, Millipore Bedford,MA), Oasis-HLB cartridges $(30 \mathrm{mg}, \mathrm{I} \mathrm{mL}$ ) and Oasis-MCX (30 mg, I mL) supplied by Waters (Milford, MA), Strata-X-C (30 mg, I mL) obtained from Phenomenex (Torrance, CA), and (I3C3)acrylamide (isotopic purity $=99 \%$ ) from Cambridge Isotope Laboratories (Andover, MA). All other chemicals and reagents were of analytical grade.

Cookie Samples. Twenty-six commercial cookies were purchased from Spanish markets. To study the effect of the baking process on the dicarbonyls, laboratory-scale experiments were carried out with model cookies. The recipe was prepared according to that of Arribas-Lorenzo et al. (24) with someminor 
modifications: $85 \mathrm{~g}$ of wheat flour, $1 \mathrm{~g}$ of salt, $25 \mathrm{~g}$ of deionized water, $24 \mathrm{~g}$ of sunflower oil, $1.2 \mathrm{~g}$ of sodiumbicarbonate, and $35 \mathrm{~g}$ of sugar. The dough was rolled to form disks with a diameter of $5 \mathrm{~cm}$ and a thickness of $2 \mathrm{~mm}$ and baked at $190^{\circ} \mathrm{C}$ from 9 to $17 \mathrm{~min}$. Samples were prepared in two parallel series and baked in an oven without forced air circulation (UNE 400, Memmert GmbH, Schwabach, Germany). Temperature was digitally controlled and monitored by software (Celsius 2007 v8.0, Memmert GmbH). All samples were finely ground and kept at $4{ }^{\circ} \mathrm{C}$ until analyses.

Determination of GO and MGO in Cookies. Samples of 0.5 ( $0.0 \mathrm{lg}$ were weighed into centrifuge tubes, and $5 \mathrm{~mL}$ of a mixture containing $20 \mathrm{mM}$ sodium phosphate buffer $(\mathrm{pH} 7.4)$ and methanol $(50: 50, \mathrm{v} / \mathrm{v})$ was added. The cookies were spiked with certain amounts of 5-MQ (internal standard). Samples were vigorously shaken for $1 \mathrm{~min}$ and centrifuged $\left(5000 \mathrm{~g}\right.$ for $10 \mathrm{~min}$ ) at $4{ }^{\circ} \mathrm{C}$. A $200 \mu \mathrm{L}$ aliquot of supernatant was mixed with $375 \mu \mathrm{L}$ of sodium phosphate buffer and $200 \mu \mathrm{L}$ of OPD (10 mM) and incubated for $3 \mathrm{~h}$ at $65-70$ ${ }^{\circ} \mathrm{C}$ in an oven (model 235, J. P. Selecta, Barcelona, Spain). After cooling, $200 \mu \mathrm{L}$ of acetic acid was added to the derivatized mixture. The sample was then loaded onto the solid phase extraction (SPE) column (OasisHLB) (the SPE step had previously been optimized, see Results and Discussion), and eluent was discharged. Next, I mL of a mixture of methanol/0.5\%acetic acid (40:60, v/v) and eluent was discharged. Finally, I mL of methanol was passed through the cartridge and the eluent collected in an Amberlite vial. The analysis was carried out at least in duplicate.

Analytical HPLC-UV Procedure for Quantification of GO and MGO. GO and MGO were measured as the corresponding quinoxalines $Q$ and 2-MQ, respectively, after derivatization with OPD using a reverse phase high-performance liquid chromatography (RP-HPLC) procedure coupled to UV detection at $315 \mathrm{~nm}$. A Shimadzu LC system (Kyoto, Japan) equipped with an LC-20ADpump, an LC-20AD/AT lowpressure gradient former, an SIL-IOADvp autosampler, a CTO-IOAS VP oven, and a DAD detector (SPDM20A) was used. Separations were carried out on anACECI8 column (5 $\mathrm{m}, 250 \_4.6 \mathrm{~mm}$, Advanced Chromatography Technologies, Aberdeen, U.K.). Elution was performed isocratically with a mixture of $0.5 \%(\mathrm{v} / \mathrm{v})$ acetic acid in water and methanol $(40: 60, \mathrm{v} / \mathrm{v})$ with a detection of $315 \mathrm{~nm}$, although UV spectra were recorded in the 190-340 $\mathrm{nm}$ range. Quantification was based on the peak area of each compound divided by the peak area of the internal standard in samples versus those found in the calibration standard. Standard stock solutions of $\mathrm{Q}$ and 2-MQ ere prepared in deionized water to a concentration of $4 \mathrm{mg} / \mathrm{mL}$. The solution was stored in the dark at 4 _C and used within 2 weeks. The standard working solution was obtained by subsequent dilution of the above-mentioned standard stock solutions with $0.5 \%(\mathrm{v} / \mathrm{v})$ acetic acid in water and methanol $(40: 60, \mathrm{v} / \mathrm{v})$ to yield concentrations of $0.0 \mathrm{I}, 0.04,0.08,0.12,0.16,0.2,0.4,0.6$, and 0.8 $\mu \mathrm{g} / \mathrm{mL}$.

Acrylamide Analysis. AA analysis was carried out by HPLC-MS according to the method of ArribasLorenzo et al. (24).

HMF Analysis. HMF determination was performed by reversed phase HPLC according to the method of Rufián-Henares et al. (25).

Food Consumption Data. An exposure study was carried out by the Spanish Ministry of Agriculture, Fishing and Food based on a yearly food consumption database (26). The statistical universe of the study compiles a balanced, representative, and stratified probability sample of the Spanish population taking into account, gender, age, region, and socioeconomic status, among other factors. An average body weight of 70 
$\mathrm{kg}$ was used to estimate the total daily intake of $\mathrm{GO}$ and MGO to total population expressed as micrograms per kilogram of body weight per day.

Statistical Analysis. Data are expressed as the mean of two or more independent determinations. Differences with $P<0.05$ were considered to be statistically significant using the Tukey test. A Microcal Origin program version 7.5 (Origin Lab Corp., Northampton, MA) was used.

\section{RESULTS AND DISCUSSION}

Derivatization. The derivatization procedure was based on a previous work (20) but with some modifications to accommodate the cookie samples. In a first step, standard solutions of target dicarbonyl compounds (GO and MGO) were used to verify the derivatization process. These standards were prepared at the same concentrations as the standard solutions of their respective quinoxalines ( $Q$ and 2-MQ), spiked with 5-MQ, and derivatized and quantified by HPLC-UV. OPD was used to derivatize GO and MGO into stable quinoxaline and 2-methylquinoxaline, respectively, and its concentration was similar to that reported on previous occasions (27). The reaction yield was determined by comparing the calibration curve data of $G O$ versus $Q$ and MGO versus $2-M Q$ with no significant differences being found $(P<0.05)$. Results showed that both curves were similar in the concentration range studied from 0.01 to $0.8 \mu \mathrm{g} / \mathrm{mL}$.

Liquid Chromatography Separation. The separation of Q, 2-MQ, and 5-MQ(internal standard) was optimized by testing two analytical columns (Kromasil ODS-2, $5 \mu \mathrm{m}, 250 \mathrm{~mm} \times 4.0 \mathrm{~mm}$, and ACE CI8, 5 $\mu \mathrm{m}, 250 \times 4.6 \mathrm{~mm})$. The ACE column produced better resolution and appearance of peak shapes despite having a longer retention time for GO and MGO (data not shown). The influence of the solvent was also investigated by comparing methanol and acetonitrile in combination with a water solution of acetic acid $(0.5 \%)$ under isocratic conditions at different percentages. The best separation was obtained with $60 \%$ methanol and $40 \%$ water acidified with $0.5 \%$ acetic acid and a flow of $0.8 \mathrm{~mL} / \mathrm{min}$. Figure la shows a chromatogram of $\mathrm{Q}$ and 2-MQ standard solutions at a concentration of $0.8 \mu \mathrm{g} / \mathrm{mL}$ each, along with 2.78 $\mu \mathrm{g} / \mathrm{mL}$ of the internal standard 5-MQ under the described optimum conditions. Retention times were 5.I, 6.I, and $8.4 \mathrm{~min}$ for Q, 2-MQ, and 5-MQ, respectively.

Optimization of the Extraction Conditions. The effect of the sample amount in the extraction step was evaluated at two sample/extraction solvent ratios of $1: 5$ and $\mathrm{l}: 10(\mathrm{~g} / \mathrm{mL})$. Methanol was chosen as an efficient solvent to extract these carbonyl compounds as indicated in previous studies (13). The study was assayed in spiked cookie samples with a known amount of GO and MGO to evaluate the yield. At the same time, the effect of different percentages of mixture solvents (30 and 50\%, v/v; methanol in sodium phosphate buffer ( $\mathrm{pH} 7.4)$ ) was also studied. Extraction efficiency improved with a sample/extraction ratio of I:I0 $(\mathrm{g} / \mathrm{mL})$ and $50 \%(\mathrm{v} / \mathrm{v})$ methanol (data not shown). Therefore, dicarbonyl extraction from cookie samples was carried out under these conditions.

Analytes were poorly resolved when the former procedure was directly applied to cookies as shown in Figure Ib. To eliminate interferences and to obtain a cleaner chromatogram and consequently increased sensitivity, the SPE procedure was carried out as a cleanup step. This purification step had previously been employed for both biological and food samples $(28,29)$. Three different SPE cartridges were tested (OasisHLB, Oasis-MCX, Strata-X-C). These cartridges were evaluated under conditions recommended by each respective supplier using as an internal reference both an unspiked cookie sample and one spiked with $Q$ and 2-MQ. In addition, standard solutions of Q, 2-MQ, and 5- MQ with increasing percentages of methanol $(0,20,40,60,80$, and $100 \%)$ in acetic acid $(0.5 \%)$ were also evaluated. Recovery, retention time, separation 
at baseline, and cleanness of the chromatogram profile were likewise assessed. Q, 2-MQ, and 5-MQ standards were effectively retained by the three cartridges, each reporting similar recoveries. However, differences in the chromatographic profile were observed when a cookie sample was used. The Oasis-HLB cartridge provided the best chromatographic separation and resolution for cookies with no interferences when the extract was finally eluted with $100 \%$ methanol. Panels b and c of Figure I show the chromatograms obtained for a cookie sample before and after the cleanup step. Recovery in the cleanup step was also studied using GO and MGO standard solutions to which the internal standard had been added before derivatization with OPD, followed by RP-HPLC analysis before being finally passed through the cartridges. Recovery by the SPE was checked by comparing the ratio area peaks of Q or 2-MQ/ 5-MQ obtained by analyzing directly the derivatized compounds prior to SPE with the same standard solutions derivatized after SPE. The recovery average obtained ranged from 90 to $106 \%$.

Although the dicarbonyls studied can be separated with good resolution within $9 \mathrm{~min}$, it was necessary to increase the elution time to allow for the elution of other peaks that could interfere in the next injection. Chromatographic separation of dicarbonyls in cookies is complex due to the likely presence of other compounds, apart from GO and MGO, such as deoxyosones (i.e., 3-deoxyglucosone), but they are not the subject of the present investigation.

Method Validation. Linearity. The linearity of the chromatographic method was calculated using $\mathrm{Q}$ and 2MQ standard solutions ranging from 0.01 to $0.8 \mu \mathrm{g} / \mathrm{mL}$ and with the internal standard at $2.78 \mu \mathrm{g} / \mathrm{mL}$. The response of both compounds was satisfactory with correlation coefficients $>0.997$. Appropriate dilution was applied to sample extracts $>0.8 \mu \mathrm{g} / \mathrm{mL}$. Table I summarizes the calibration data for GO and MGO.

Repeatability and Reproducibility. The repeatability and reproducibility were determined by replicate analyses of a cookie sample. The precision values are presented in Table 2 as well as the concentrations of GO and MGO in the sample. The assay was performed using relative standard deviation (RSD, \%) and calculated by analyzing five replicates over a period of 3 days. The results obtained for both dicarbonyls showed RSD of $<7 \%$, indicating that the precision of the method was satisfactory.

Recovery. Table 3 gives the recovery results obtained for GO and MGO. Accuracy was determined by measuring the percentage of recovery after spiking a cookie sample with three different levels of GO and MGO standard solutions and $25 \mu \mathrm{L}$ of the internal standard prior to the derivatization process. The recovery obtained for both compounds ranged from 97 to II4\% with RSDs of $<8 \%$ at different spiking levels.

Limits of Detection (LOD) and Quantification (LOQ). The LOD and LOQ were determined by calculating the standard deviation of the area divided by the slope and multiplying by 3.33 and 10 , respectively. Table I summarizes the LOD and LOQ obtained, although lower detection limits could easily be achieved if needed by applying a preconcentration step after cleanup.

Application to Commercial Cookies. The in-house validated method was applied in the analysis of 26 commercial cookies taken randomly from different local markets in Madrid (Spain) to obtain information on the distribution of these dicarbonyls and then to estimate population exposure to them. As cookies comprise a heterogeneous food commodity group because they are composed of a great variety of ingredients (Table 4), traditional sweets, breakfast, and dietetic cookies were also included in this study. Table 5 summarizes the results obtained from the samples. GO content ranged from 4.8 to $26.0 \mathrm{mg} / \mathrm{kg}$ with 
a mean value of $15.0 \mathrm{mg} / \mathrm{kg}$ and a median of $16.4 \mathrm{mg} / \mathrm{kg}$. MGO content ranged from 3.7 to $81.4 \mathrm{mg} / \mathrm{kg}$ with a mean value of $29.9 \mathrm{mg} / \mathrm{kg}$ and a median of $16.6 \mathrm{mg} / \mathrm{kg}$.

So far, numerous studies have found these dicarbonyls in foodstuffs such as beer, honey, butter, wine, and fermented foods, products in which these compounds were most frequently detected. However, published data on bakery products is scarce, so a systematic study is necessary before any risk assessment can be carried out. GO and MGO were detected at concentrations of 0.3 and $0.79 \mathrm{mg} / \mathrm{kg}$, respectively, in bread, and in the case of toast the amounts reported were 0.5 and $2.5 \mathrm{mg} / \mathrm{kg}$ for GO and MGO(I8). Roiter and Borovikova (30) also showed that bread crust and bread crumbs contained $\mathrm{GO}$ at concentrations of up to $1.6 \mathrm{mg} / \mathrm{kg}$. However, no studies have been found on the detection of these dicarbonyls in cookies. The GO and MGO levels in cookies found in our work were about 10 -fold higher than those obtained for bakery products and could result from differences in the formulation and processing of the cookies and bread. In general, cookie formulation is more complex and contains ingredients such as reducing sugars and probably unsaturated oils, which are precursors of these dicarbonyls through the Maillard reaction, caramelization, or lipid oxidation. It is known that MGO is formed by retroaldolization of the intermediate 3-deoxyglucosulose (3I) and that $\mathrm{GO}$ is mainly a product of autoxidation of glucose (32). In comparison, bread derivates are mainly made up of wheat flour, baking powder, salt, and water, so dicarbonyl levels would be expected to be lower.

By a closer scrutinization of the data it can be seen that seven cookie samples showed higher values in comparison with the rest, all of them with MGO values above $52.2 \mathrm{mg} / \mathrm{kg}$ and up to $81.4 \mathrm{mg} / \mathrm{kg}$. It was observed that cookies containing ammonium bicarbonate and fructose as ingredients (Table 4) formed more MGO, thus confirming that ammonium bicarbonate and fructose facilitate the generation of these dicarbonyl compounds (23).

To estimate the dietary exposure of Spanish consumers to dicarbonyls from cookies, the national tables of food consumption for 2008 were used (26). Although the point estimate (deterministic approach) does not assess the probability or uncertainty or even identify high-risk consumers, because it is based on population and not on subjects, it is nevertheless a first approximation and a useful screening tool for designing a more specific study should there be a potential risk. Overall population exposures to dicarbonyls from cookies were estimated to be 213 and $216 \mu \mathrm{g} /$ person/day for GO and MGO, respectively.

Mapping of Dicarbonyl Distribution in Commercial Cookies. Six independent samples with different shapes, thicknesses, and apparently different baking technologies according to their brownness (visual appreciation) were chosen to get a broad view of the distribution of GO and MGO in different zones of the cookie. Representative portions of the upper side (US), lower side (LS), center side (CS), and border side (BS) of the sample cookie were obtained to map the contribution of each fraction to that of the whole cookie. On average, GO and MGO formations were significantly higher in US and BS portions as expected, regardless of the shape or thickness of the cookie, because water evaporation and temperature are higher in these parts of the cookie, subsequently enhancing both caramelization and the Maillard reaction. Furthermore, considerable variability was observed due to sample heterogeneity because there could be up to a 3-fold difference in GO content between the upper and lower sides in some samples. These results clearly showed that GO and MGO contents in cookies were not uniformly distributed.

Effect of Processing Conditions. The influence of baking conditions on GO and MGO in cookies baked at $190^{\circ} \mathrm{C}$ for $9,11,13,15$, and 17 min was investigated. As shown in Figure 2, amounts of both GO and 
MGO increased linearly with time, reaching up to 16.1 and $15.3 \mathrm{mg} / \mathrm{kg}$ for $\mathrm{GO}$ and MGO, respectively. Values were higher for GO than for MGO, probably due to its formation by sugar oxidation during the heating process, unlike MGO which is enhanced by the Maillard reaction (32). In general, levels were found to be lower than those detected in commercial samples, possibly due not only to the different baking processes but also again to the type of sugar used in the formulation be it syrup, inverted sugar, or honey. Cookies were prepared in the laboratory with sucrose as the only sugar ingredient because earlier experiments had demonstrated that the use of a non reducing sugar such as sucrose formed less dicarbonyls than it would if used in conjunction with glucose or fructose (23). Apart from the foregoing, these reactive compounds can undergo multiple reactions and form other compounds such as melanoidins at more advanced stages of the reaction (see, e.g., ref 33). Nevertheless, despite the small amounts detected, it was clear that the baking process markedly accelerated the formation of these compounds, confirming previous data such as that of Daglia et al. (29), who demonstrated that the content of R-dicarbonyl compounds was influenced by the roasting process of coffee. Moreover, it was observed that dicarbonyls had already been detected in dough before fermentation, indicating that the dough fermentation process may have started when the baking agent was added because it has been reported that both dicarbonyls are formed in fermented food (I3).

Relationship with Acrylamide and HMF. Acrylamide has been identified by many as a heat-induced toxicant in foodstuffs, formed by the reaction between a reducing sugar and asparagine in the Maillard reaction $(34,35)$. Its formation is greatly facilitated by high temperatures (above $120^{\circ} \mathrm{C}$ ) in processes such as frying, baking, or roasting (36). To date, several studies have demonstrated the role of R-dicarbonyl compounds in the formation of acrylamide following the Strecker degradation pathway $(23,34)$. Recently, Yuan et al. (37) showed clearly that MGO is the reaction precursor of acrylamide and accounts for nearly $80 \%$ of its formation in aqueous Maillard reaction models (Glc/Asn).

In our study, former correlation with model systems was also demonstrated in cookies prepared at laboratory scale and in commercial samples as well. Figure 3a shows acrylamide content and dicarbonyl levels of cookies at laboratory scale at different baking times. The yield of acrylamide and dicarbonyls was positively correlated during baking under controlled conditions. These results for cookies are also in line with the literature, in which it has been reported that these reactive intermediates of the Maillard reaction interact with asparagine, forming acrylamide in model systems (34). As described in model systems (37), formation of dicarbonyls, as precursors of $A A$, accumulates during the first stages of baking until AA formation is observed.

Figure 4 registers the levels of MGO and acrylamide in commercial cookies. Seven cookie samples show substantially higher amounts of MGO (from 52.2 to $81.4 \mathrm{mg} / \mathrm{kg}$ ) and acrylamide (from 1200 to $2100 \mu \mathrm{g} / \mathrm{kg}$ ) in comparison with the rest of the samples that contain up to $29.7 \mathrm{mg} / \mathrm{kg}$ for MGO and I $200 \mathrm{\mu g} / \mathrm{kg}$ for AA. This difference might be the result of sample variability produced not only by the choice of baking processes but also by recipe variations. However, if cookie composition (Table 4) is observed, results show that the lowest levels of MGO and acrylamide are found in those cookies which contain ingredients such as sucrose, glucose, or sodium bicarbonate. Cookies with the highest levels were those elaborated especially with ammonium bicarbonate or fructose instead of glucose or sodium bicarbonate. This replacement gave rise to an increase in acrylamide and MGO levels. Similar behavior has been described in model systems in other published work. Amrein et al. (23) demonstrated that the baking agent ammonium bicarbonate promoted the formation of more dicarbonyl compounds compared with sodium bicarbonate and even more in the presence of fructose. Thus, it is important to stress that this finding confirmed that acrylamide formation is 
related to these reactive intermediates in real samples. However, no correlation was observed between GO and AA levels in commercial cookies because GO, unlike AA, is not the predominant R-dicarbonyl fragment formed by the Maillard reaction. Carbohydrate fragmentation is enhanced by alkaline conditions and subsequently, by the formation of sugar fragments with an $\mathrm{R}$ dicarbonyl moiety. Therefore, it is reasonable to find higher levels of MGO and GO in commercial samples with ammonium bicarbonate as the leavening agent.

With regard to HMF, it is formed either in the Maillard reaction or by caramelization, but significantly HMF did not correlate with either GO or MGO in commercial cookies (data not shown), in contrast to acrylamide. However, in cookies prepared at laboratory scale at different times, a correlation was observed (Figure 3b). At the beginning, HMF and dicarbonyl amounts were basically low, indicating that an induction period was necessary to form these compounds. However, after 15 min of baking time, a large increase in HMF formation was observed, whereas dicarbonyl compounds only increased slightly. This revealed that HMF formation was highly dependent on temperature in contrast to dicarbonyls that were formed in previous stages of the reaction. Furthermore, similar behavior was observed in both dicarbonyls. GO and MGO formation can result from isomerization and subsequent retro-aldolization of sugar or by cleavage or 3-deoxyhexulose (II), but MGO is formed to a larger extent under MR conditions, especially through degradation of the Amadori product more than during caramelization.

In conclusion, analysis of GO and MGO in foods is difficult because they are very reactive, easily polymerized, and volatile substances. The in-house validated RP-HPLC-UV method described in this paper permitted the determination of GO and MGO levels in cookies after derivatization to stable quinoxaline derivatives and a cleanup step. GO and MGO were widely distributed in commercial cookies in a broad range of concentrations but mostly present at the surface of the cookie. Because GO and MGO may be involved in the early stages of many age-related human diseases $(4,5)$, it is of relevance to evaluate their dietary exposure. Under controlled baking conditions, formation of dicarbonyl compounds was related to the baking time and, subsequently, to the formation of both acrylamide and HMF. Finally, this study revealed for the first time that there is a significant correlation between MGO and acrylamide in commercial cookie samples, thus confirming the important role of dicarbonyls in the formation of these heat-induced contaminants in foods.

\section{ACKNOWLEDGMENT}

Silvia de la Peña and M. A. Martínez are gratefully acknowledged for their technical assistance. This research has been partly funded under Project ANALYSIC (S-505/AGR-03/2) by the Autonomous Community of Madrid and the Spanish Ministry of Science and Technology (AGL 2005-0I735). G.A.-L. is grateful to the Conserjería de Educación de la Comunidad de Madrid and Fondo Social Europeo for her Ph.D. grant.

\section{LITERATURE CITED}

(I) Thornalley, P. J. Dicarbonyl intermediates in the Maillard reaction. Ann. N.Y. Acad. Sci. 2005, I043, II I117.

(2) Talukdar, D.; Chaudhuri, B. S.; Ray, M.; Ray, S. Critical evaluation of toxic versus beneficial effects of methylglyoxal. Biochemistry (Moscow), 2009, 74, 1059-1069.

(3) Lapolla, A.; Flamini, R.; Lupo, A.; Arico, N. C.; Rugiu, C.; Reitano, R.; Tubaro, M.; Ragazzi, E.; Seraglia, R.; Traldi, P. Evaluation of glyoxal and methylglyoxal in uremic patients under peritoneal dialysis. Ann. N.Y. Acad. Sci. 2005, 1043, 217-224. 
(4) Thornalley, P. J. Glycation free adduct accumulation in renal disease: the new AGE. Pediatr. Nephrol. 2005, 20, 15I5-1522.

(5) Kalapos, M. P. Methylglyoxal in living organisms: chemistry, biochemistry, toxicology and biological implications. Toxicol. Lett. 1999, I10, I45-175.

(6) Baskaran, S.; Balasubramanian, K. A. Toxicity of methylglyoxal towards rat enterocytes and coloncytes. Biochem. Int. 1990, 21, 165-174.

(7) Ueno, H.; Nakamuro, K.; Sayato, Y.; Okada, S. DNA lesion in rat hepatocytes induces by in vitro and in vivo exposure to glyoxal. Mutat. Res. 1991, 260, II5-119.

(8) Schnuch, A.; Uter, W.; Geier, J.; Frosch, P. J.; Rustemeyer, T. Contact allergies in healthcare workers. Results from the IVDK. Acta Derm. Venereol. 1998, 78, 358-363.

(9) Uter, W.; Schwanitz, H. J.; Lessmann, H.; Schnuch, A. Glyoxal is an important allergen for (medical care) cleaning staff. Int. J. Hyg. Environ. Health 200I, 204, 25I-253.

(I0) Nemet, I.; Varga-Defterdarovic, L.; Turk, Z. Methylglyoxal in food and living organisms. Mol. Nutr. Food Res. 2006, 50, II5-II7.

(I I) Homoki-Farkas, P.; € Orsi, F.; Kroh, L. W. Methylglyoxal determination from different carbohydrates during heat processing. Food Chem. 1997, 59, 157-163.

(I2) Niyati-Shirkhodaee, F.; Shibamoto, T. Gas-chromatographic analysis of glyoxal and methylglyoxal formed from lipids and related compounds upon ultraviolet-irradiation. J. Agric. Food Chem. 1993, 4I, 227-230.

(I3) Yamaguchi, M.; Ishida, J.; Xuan-Xuan, Z.; Nakamura, M.; Yoshitake, T. Determination of glyoxal, methylglyoxal, diacethyl, and 2,3-pentanedione in fermented foods by high-performance liquid chromatography with fluorescence detection. J. Liq. Chromatogr. 1994, 17, 203-2II.

(14) Weigel, K. U.; Opitz, T.; Henle, T. Studies on the occurrence and formation of I,2-dicarbonyls in honey. Eur. Food Res. Technol. 2004, 218, 147-157.

(I5) De Revel, G.; Bertrand, A. A method for the detection of carbonyl compounds in wine: glyoxal and methylglyoxal. J. Sci. Food Agric 1993, 6I, 267-272.

(16) Barros, A.; Rodrigues, J. A.; Almeida, P. J.; Oliva-Teles, M. T. Determination of glyoxal, methylglyoxal and diacetyl in selected beer and wine by HPLC with UV spectrophotometric detection after derivatization with o-phenylendiamine. J. Liq. Chromatogr. Relat. Technol. 1999, 22, 206I-2069.

(17) Hirayama, T.; Yamada, N.; Nohara, M.; Fukui, S. The existence of the I,2-diacrbonyl compounds glyoxal, methylglyoxal and diacetyl in autoxidised oils. J. Sci. Food Agric. 1984, 35, I357-1362.

(18) Nagao, M.; Fujita, Y.; Sugimura, T.; Kosuge, T. Methylglyoxal in beverages and foods: its mutagenicity and carcinogenicity. IARC Sci. Publ. 1986, 70, 283-29I.

(19) Thornalley, P. J.; Langborg , A.; Minhas, H. S. Formation of glyoxal, methylglyoxal and 3-deoxyglucosone in the glycation of proteins by glucose. Biochem. J. 1999, 344, 109-1 16.

(20) De Revel, G.; Pripis-Nicolau, L.; Berbe, J. C.; Bertrand, A. The detection of R-dicarbonyl compounds in wine by formation of quinoxaline derivates. J. Sci. Food Agric. 2000, 80, 102-108.

(21) Acrylamide; International Agency for Research on Cancer: Lyon, France, 1994.

(22) Surh, Y.; Tannenbaun, S. Activation of the Maillard reaction product 5-(hydroxymethyl)furfural to strong mutagens via allylic sulfonation and chlorination. Chem. Res. Toxicol. 1994, 7, 313-3 I8.

(23) Amrein, T. M.; Andres, L.; Manzardo, G. G. G.; Amado, R. Investigations on the promoting effect of ammonium hydrogencarbonate on the formation of acrylamide in model system. J. Agric. Food Chem. 2006, 54, 10253-10261.

(24) Arribas-Lorenzo, G.; Fogliano, V.; Morales, F. J. Acrylamide formation in a cookie system as influenced by the oil phenol profile and degree of oxidation. Eur. Food Res. Technol. 2009, 229, 63-72. 
(25) Rufián-Henares, J. A.; Delgado-Andrade, C.; Morales, F. J. Application of a fast HPLC method for simultaneously determination of furanic compounds and glucosylisomaltol in breakfast cereals. J. AOAC Int. 2006, 89, 16I-165.

(26) MARM. La Alimentación en España; Ministerio de Agricultura, Pesca y Alimentación: Madrid, Spain, 2009.

(27) Dhar, A.; Desai, K.; Liu, J.; Wu, L. Methylglyoxal, protein binding and biological samples: are we getting the true measure? J. Chromatogr., B 2009, 877, 1093-1100.

(28) Gildersleeve, D. L.; Tobes, M. C.; Natale, R. B. Rapid analysis for methylglyoxal bis(guanylhydrazone) by reversed-phase ion-pair liquid chromatography. Clin. Chem. 1985, 31, 1979-1984.

(29) Daglia, M.; Papetti, A.; Aceti, C.; Sordelli, B.; Spini, V.; Gazzani, G. Isolation and determination of Rdicarbonyl compounds by RPHPLC-DAD in green and roasted coffee. J. Agric. Food Chem. 2007, 55, 8877-8882.

(30) Roiter, I. M.; Borovikova, L. A. Level of volatile carbonyl compounds in bread during the addition of enzyme preparations. Khlebopek. Konditer. Promst. 1972, 14, 14-15.

(3I) Weenen, H. Reactive intermediates and carbohydrate fragmentation in Maillard chemistry. Food Chem. 1998, 62, 393-40I.

(32) Wells-Knecht, K. J.; Zyzak, D. V.; Litchfield, J. E.; Thorpe, S. R.; Baynes, J. W. Mechanism of autoxidative glycosylation: identification of glyoxal and arabinose as intermediates in the autoxidative modification of proteins by glucose. Biochemistry 1995, 34, 3702- 3709.

(33) Hayashi, T.; Namiki, M. Role of sugar fragmentation in an early stage browning of amino-carbonyl reaction of sugar with amino acid. Agric. Biol. Chem. 1986, 50, 1965-1970.

(34) Mottram, D. S.; Wedzicha, B. L.; Dodson, A. T. Acrylamide is formed in the Maillard reaction. Nature 2002, 4I9, 449-450.

(35) Stadler, R. H.; Blank, I.; Varga, N.; Robert, F.; Hau, J.; Guy, P. A.; Robert, M. C.; Riediker, S. Acrylamide from Maillard reaction products. Nature 2002, 419, 449-450.

(36) Tareke, E.; Rydberg, P.; Karlsson, P.; Eriksson, S.; Tornqvist, M. Analysis of acrylamide, a carcinogen formed in heated foodstuffs. J. Agric. Food Chem. 2002, 50, 4998-5006.

(37) Yuan, Y.; Zhao, G-h.; Hu, X-s.; Wu, J-h.; Liu, J.; Chen, F. High correlation of methylglyoxal with acrylamide formation in glucose/ asparagine Maillard reaction model. Eur. Food Res. Technol. 2008, 226, |30|-|307. 


\section{FIGURES AND TABLES}

Table I. Calibration Data (Correlation Coefficient, r, and Regression Equation), Limits of Detection (LOD), and Limits of Quantification (LOQ) for Analysis of Dicarbonyl Compounds in Cookies (a)

\begin{tabular}{|c|c|c|c|c|}
\hline \multirow[b]{2}{*}{ compound } & \multicolumn{2}{|c|}{ calibration data } & \multirow[b]{2}{*}{$\mathrm{LOD}(\mu \mathrm{g} / \mathrm{mL})$} & \multirow[b]{2}{*}{$\mathrm{LOQ}(\mu \mathrm{g} / \mathrm{mL})$} \\
\hline & $r$ & equation & & \\
\hline glyoxal & 0.999 & $330.67 x+3.76$ & 0.01 & 0.03 \\
\hline methylglyoxal & 0.997 & $367.72 x+0.76$ & 0.02 & 0.04 \\
\hline
\end{tabular}

${ }^{a}$ Concentration range applied from 0.01 to $0.8 \mu \mathrm{g} / \mathrm{mL}$.

Table 2. Repeatability and Reproducibility Values of the HPLC-UV Procedure for Analysis of Glyoxal and Methylglyoxal in Cookies (a)

\begin{tabular}{|c|c|c|c|c|c|}
\hline \multirow[b]{2}{*}{ compound } & \multicolumn{3}{|c|}{ mean $(\mathrm{mg} / \mathrm{kg}) \pm \mathrm{SD}$} & \multirow{2}{*}{$\begin{array}{l}\mathrm{RSD}(\%) \\
\text { repeatability }\end{array}$} & \multirow{2}{*}{$\begin{array}{l}\text { RSD }(\%) \\
\text { reproducibility }\end{array}$} \\
\hline & day 1 & day 2 & day 3 & & \\
\hline glyoxda & $15.4 \pm 0.9$ & $16.5 \pm 0.8$ & $16.7 \pm 1.1$ & 5.8 & 4.3 \\
\hline methylglyoxal & $51.8 \pm 3.1$ & $55.7 \pm 2.8$ & $58.3 \pm 4.8$ & 6.4 & 5.9 \\
\hline
\end{tabular}

${ }^{a}$ The assay was carried out on three different days with five replicates each. SD, standard deviation; RSD, relative standard deviation.

Table 3. Recovery (Mean +- RSD) of the Dicarbonyls from a Cookie Sample at Different Spiking Levels $(n=$ 5)

\begin{tabular}{lccc}
\hline & \multicolumn{3}{c}{ recovery (\%) at spiking level of } \\
\cline { 2 - 4 } compound & $0.08 \mu \mathrm{g} / \mathrm{mL}$ & $0.4 \mu \mathrm{g} / \mathrm{mL}$ & $0.8 \mu \mathrm{g} / \mathrm{mL}$ \\
\hline glyoxal & $102 \pm 7$ & $107 \pm 3$ & $114 \pm 2$ \\
methylglyoxal & $99 \pm 2$ & $97 \pm 4$ & $103 \pm 4$ \\
\hline
\end{tabular}


Table 4. Ingredients of Commercial Cookies (a)

\begin{tabular}{llll}
\hline cookie & \multicolumn{1}{c}{ sugars } & cereal & $\mathrm{NH}_{4} \mathrm{HCO}_{3}$ \\
\hline 1 & sucrose, syrup & W & \\
2 & sucrose, glucose syrup & O & yes \\
3 & sucrose, glucose syrup & W & \\
4 & sucrose, glucose syrup & W & \\
5 & fructose & W, R, Z, Y & yes \\
6 & sugar, honey & W & \\
7 & sucrose & W & \\
8 & sucrose, glucose & W, R & \\
9 & sucrose, glucose syrup, caramel & W & \\
10 & sucrose, glucose, fructose syrup & W & \\
11 & sucrose, glucose syrup & W & \\
12 & sucrose, glucose, fructose syrup & W & \\
13 & fructose & W & yes \\
14 & sucrose, glucose syrup & W & \\
15 & fructose & W & yes \\
16 & maltitol, lactitol, caramel & W & \\
17 & sucrose, glucose syrup & W, R, M & \\
18 & sucrose, glucose, fructose syrup & W, O & \\
19 & sucrose, glucose, fructose syrup, honey & W, O, Y & \\
20 & sucrose, glucose, fructose syrup, honey & W, O & \\
21 & fructose & W & yes \\
22 & fructose & W, O & yes \\
23 & fructose & W & \\
24 & fructose & W, R, Z, Y & yes \\
25 & sucrose, glucose syrup & W & \\
26 & sucrose, glucose syrup, honey & W & \\
\hline & & & \\
\hline
\end{tabular}

${ }^{a}$ Wheat $(W)$, oat $(O)$, maize $(Z)$, rice $(R)$, malt $(M)$, and rye $(Y)$.

Table 5. Occurrence of Glyoxal and Methylglyoxal in Commercial Cookies

\begin{tabular}{lcc}
\hline & glyoxal $(\mathrm{mg} / \mathrm{kg})$ & methylglyoxal $(\mathrm{mg} / \mathrm{kg})$ \\
\hline mean & 15.0 & 29.9 \\
standard deviation & 5.2 & 25.9 \\
minimum & 4.8 & 3.7 \\
25th percentile & 11.4 & 12.1 \\
median & 16.4 & 16.6 \\
75th percentile & 18.7 & 46.6 \\
95th percentile & 26.0 & 81.4 \\
maximum & 20.5 & 78.0 \\
\hline
\end{tabular}


Figure I. Chromatograms of quinoxaline derivatives of glyoxal (GO) and methylglyoxal (MGO) and internal standard of 5-methylquinoxaline (5-MQ) detected at $315 \mathrm{~nm}$ : standard solutions (a); cookie sample before cleanup step (b); cookie sample after cleanup step (c).
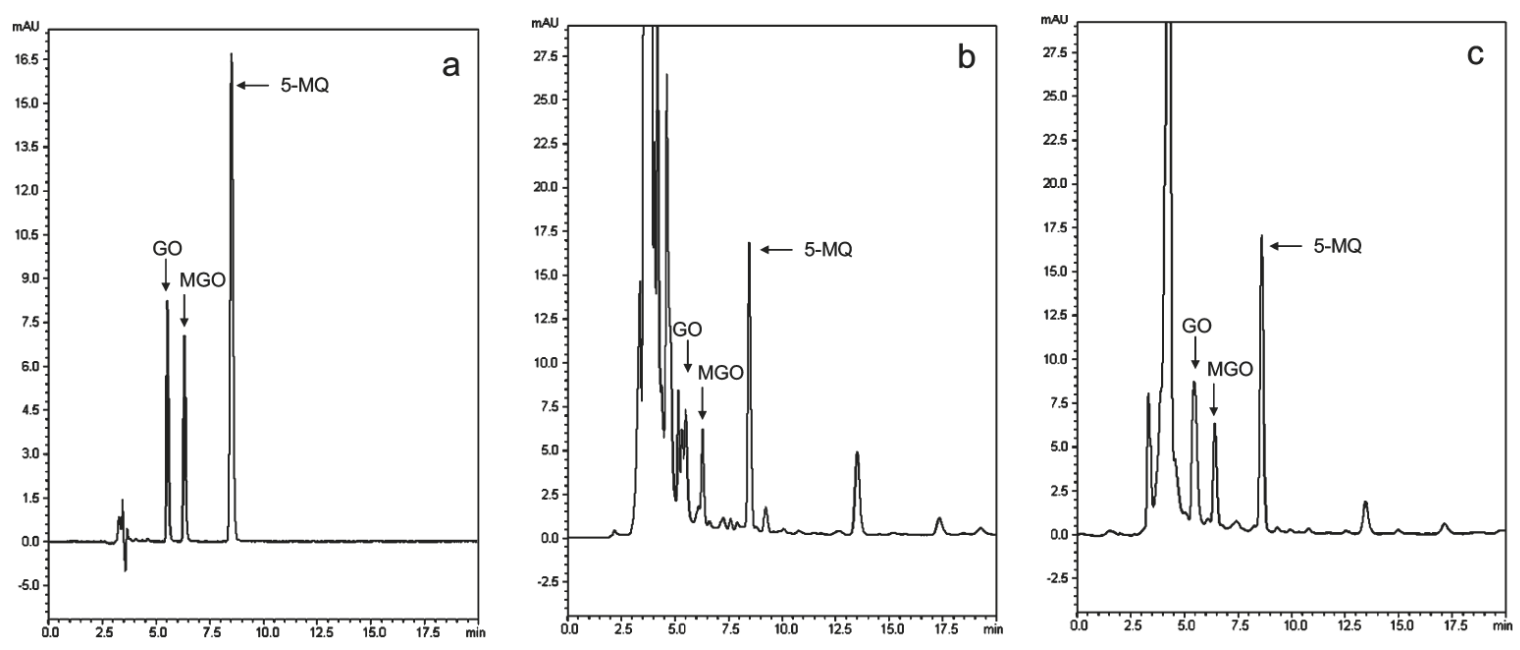

Figure 2. Influence of baking time ( $\mathrm{min}$ ) on formation of glyoxal (GO) and methylglyoxal (MGO) in cookies prepared at laboratory scale at $190^{\circ} \mathrm{C}$.

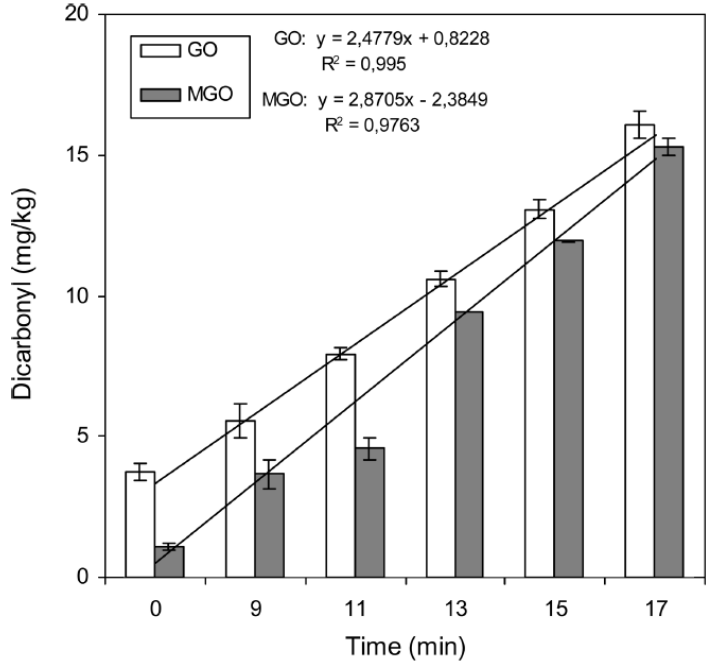


Figure 3. Relationship between dicarbonyls and acrylamide (a) and HMF (b) levels in cookies baked at 190 ${ }^{\circ} \mathrm{C}$ for different times. AA, acrylamide; GO, glyoxal; MGO, methylglyoxal.
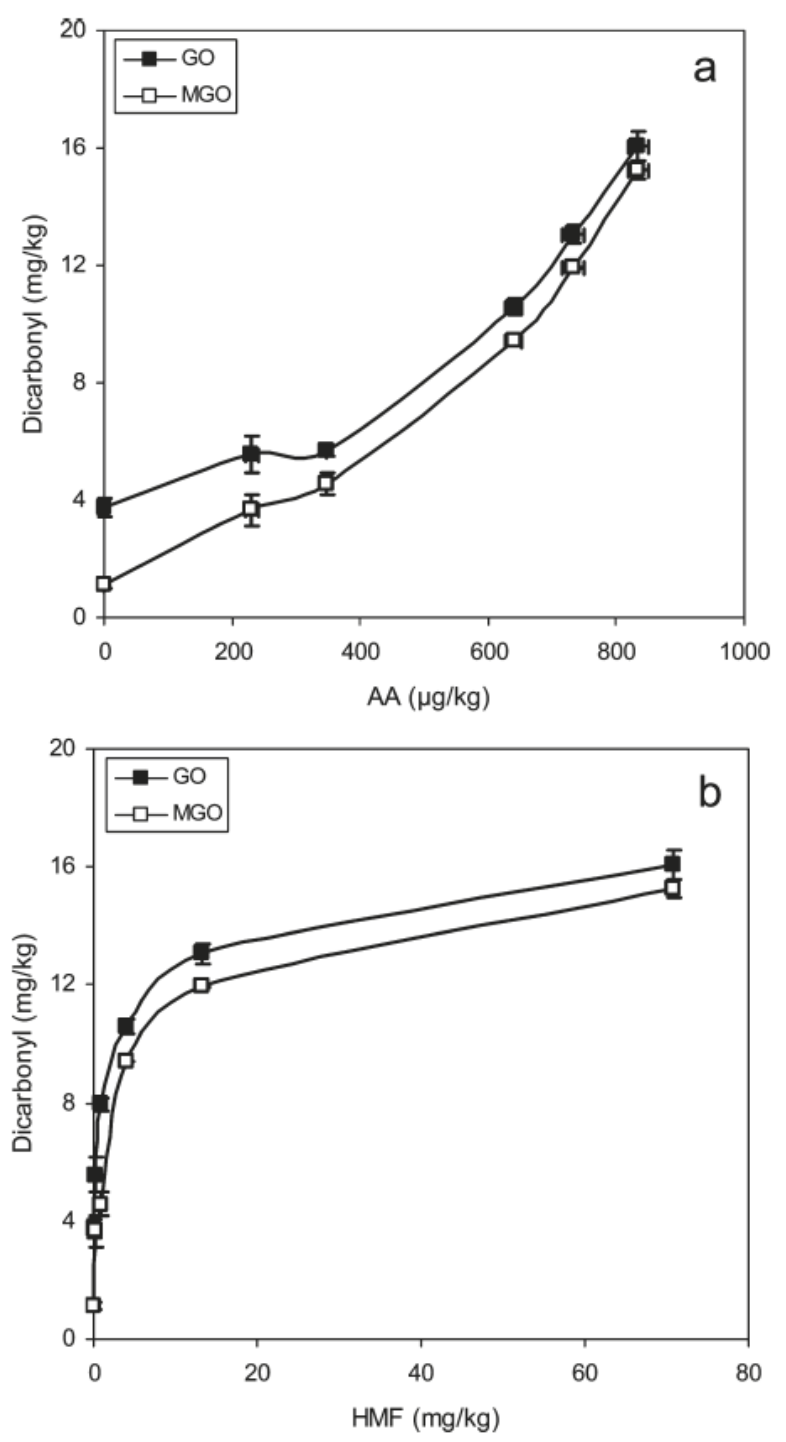
Figure 4. Relationship between methylglyoxal (MGO) and acrylamide (AA) in commercial cookies. Numbers correspond to cookie samples identified in Table 4.

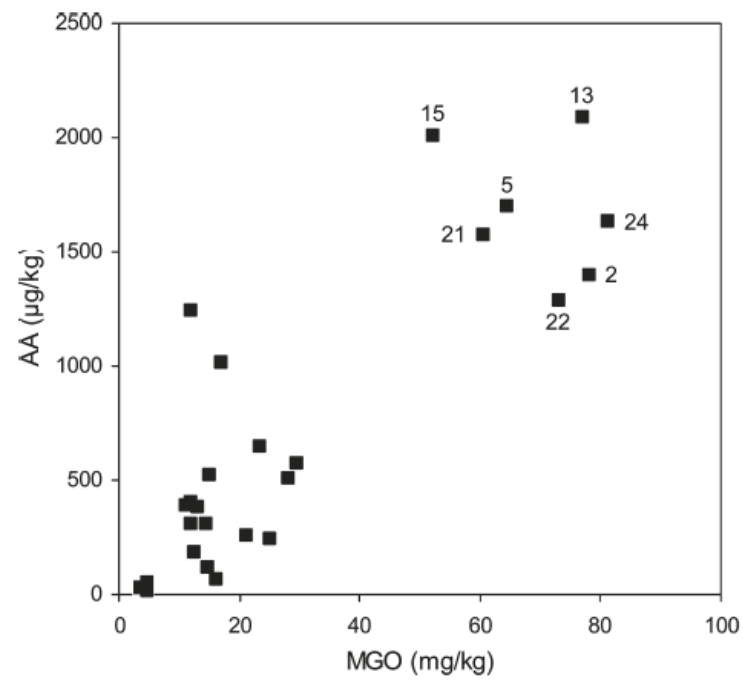

